\title{
The Effect of Severity of Addiction and Abstinence Self- efficacy to Drug Craving in Narkotics Abusers
}

\author{
Kenes Pranandari Wibowo \\ kenespranandari05@gmail.com \\ Gunadarma University, Margonda Raya, Depok 16424, Indonesia
}

\begin{abstract}
Drug craving is a subjective motivation where users feel they want to go back to using narcotics. Drug craving is closely related to relapse. Rehabilitation carried out will be in vain when the abuser has stopped using narcotics but then reuse (relapse), so it is important to know what factors can influence drug craving. This study aims to examine the effect of the severity of addiction and abstinence self efficacy on drug craving in drug abusers. In this study, there were 100 stimulant narcotics abusers who were running a rehabilitation program somewhere. Data were analyzed using multiple regression analysis. The results showed that there was a significant effect of addiction severity and abstinence of self efficacy on drug craving with a significant value of $0.000(\mathrm{p}<0.05)$.
\end{abstract}

Published by IJRP.ORG. Selection and/or peer-review under responsibility of International Journal of Research Publications (IJRP.ORG)

Keyword : Drug Craving, Severity of Addiction, Abstinence Self Efficacy

\section{Introduction}

One problem that has not yet been resolved is the problem related to narcotics addiction where the number of abusers is increasing. Generally narcotics used to get pleasure also get the enthusiasm needed to work. One type of narcotics used to increase work productivity, which is a type of stimulant. Where the function of this stimulant is more specifically, which works through neurotransmitters of norepinephrine and dopamine. Norepinephrine is responsible for energy, encouragement, motivation, and creativity, while dopamine is responsible for regulation of mood and pleasant experience. Thus, stimulants make users feel an increase in energy and endurance, increased mood and alertness, attention and memory, as well as euphoria (Thakar, 2006)

Because of the pleasant effects and stimulation on the productivity of this work, drug users, especially the types of stimulants find it difficult to escape from these substances. Moreover, with the use of substances related to conditions in the brain, that narcotics addiction is a disorder in the brain because narcotics changes how the body and brain communicate (McGhee, 2011). Excessive use of narcotics can cause the brain to inform that the body needs narcotics to survive (Hall, Carter \& Forlini, 2015 ; McGhee, 2011 ; Volkow et.al, 2010). Narcotics abuse is difficult to stop because it is related to the process of learning and memory (Fleischhacker \& Brooks, 2003). The part of the brain that plays an important role in learning and memory is the hippocampus. The brain has internalized that the effects of substances used are very 
pleasant, giving rise to the desire to reuse these substances (Fleischhacker \& Brooks, 2003 ; Kutlu \& Gould, 2016 ; Silva, Galinato \& Mandyam, 2016]. This condition is usually termed drug craving.

Drug craving is considered a key element of relapse. Experts say that drug craving is associated with complex physiological interactions of neurotransmitters in the brain, namely dopamine and glutamate. Drug craving is influenced by environmental signals associated with pleasant effects of substance use or it can be said to evoke memories of the "gifts" given by substance use in this case the effects of substances are pleasant (Ekhtiari, Nasseri, Yavari, Mokri \& Monterosso, 2016 ; Kamboj \& Das, 2017 ; Nutt \& Nestor, 2013). Further explained that when looking at environmental signals, dopamine is released in the middle brain, which is in the accumben nucleus and ventral striatum which then activates the memory scheme and learning scheme in the amygdala and hippocampus. Then the projection of dopamine is received by the dorsolateral prefrontal cortex in the brain on the front upper edge. This area is also involved in inhibitory response, verbal fluency, planning, organizing skills, reasoning, and problem solving (Funk, Coen, Tamadon, Hope, Shaham, \& Lê, 2016 ; Nutt \& Nestor, 2013 ; Padula, McQueeny, Lisdahl, Price \& Tapert, 2015). In the Elaborated Intrusion (EI) theory, it is said that drug craving is described as a cognitive condition that is manifested through sensory images that are similar to those that give rise to the desire to reuse narcotics that are influenced by the picture of achieving goals, in this case using narcotics (Skorka-Brown, Andrade, Whalley \& May, 2015). The desire to reuse narcotics is directed by a description of the experience of achieving goals. Furthermore, it was explained that craving is more influenced by visual images. In craving conditions, a description of the pleasant experience of past narcotics usage arises automatically because the information is accessed from memory which then directs the addict to elaborate (Knäuper, Pillay, Lacaille, McCollam \& Kelso, 2011).

Relapse is associated with high craving conditions (Girardeau, Navailles, Durand, VouillacMendoza, Guillem \& Ahmed, 2016 ; Venniro, Caprioli, \& Shaham, 2018). Research conducted by Killen and Fortmann (1997) in 2600 smokers, showed that $32 \%$ of respondents who reported high levels of craving then relapse within 1 week after quitting smoking. Research conducted by Schneekloth et al. (2012) on cigarette smokers, which are also addictive substances, suggests that a considerable factor in the cause of relapse is craving. Because of the close relationship between drug craving and relapse, it is important to look at any factors that can affect drug craving both those that have a positive effect and those that have a negative effect on drug craving, so that relapse can be anticipated. One of the factors that can influence drug craving, namely the severity of the abuser itself (the severity of addiction).

Severity is a relevant concept for individuals or populations in determining how much resources can be devoted to addiction problems. The severity of addiction includes health problems, narcotics use, legal status, family problems, problems in the school or workplace, problems with social activities and interactions, as well as problems with the psychological status of narcotics abusers. The study saw that there was an influence on the severity of drug craving addiction, namely a study conducted by Soenksen, Stein, Brown, Stenge, Rossi, and Lebeau (2015) on 93 narcotics abusers, aged 12-18 years consisting of various races. The results show that there is an influence between the severity of withdrawl symptoms and the level of drug craving, where the higher the severity of the drug, the higher the level of drug craving. Another study was conducted by De los cobos, Siñol, Trujols, Bañuls, Batlle and Tejero (2011) which aimed to characterize the reporting of drug craving in 32 cravers and 45 non cravers who had undergone a 14-day detoxification program. The results show that users who report the absence of drug craving can be characterized by lower addiction severity. In a study conducted by Vollstädt-Klein, Kobiella, Bühler, Graf, Fehr, Mann \& Smolka (2011) involving 22 smokers and 21 non-smokers, the results showed that smokers with moderate severity, when shown advertisements about cigarettes, hence there is an increase in activation in the amygdala, hippocampus, putamen, and thalamus which are parts of the brain associated with craving, whereas in smokers with high dependency severity, more are influenced by internal cues such as withdrawal. Another study was conducted by Canterberry, Hanlon, Hartwell, Li, Owens, LeMatty, \& George (2013) who examined brain 
activity associated with craving, namely the anterior cingulate cortex (ACC) involving 9 smokers. It was found that in individuals with lower dependency severity, more success reduced ACC activation.

One of the other factors that can be estimated can also influence drug craving, namely the belief in one's ability to organize the resources owned to deal with situations in life (Melander, 2002). This selfconfidence is commonly called self efficacy. Self efficacy in the context of addiction is when an individual believes that he will not use narcotics in certain situations (abstinence). Some studies see that self efficacy influences drug craving, namely Chong and Lopez (2008) who examined predictors affecting relapse in Indian women using drugs, it was found that very high self efficacy influenced the desire not to use drugs. In addition, Tuliau and Liwag (2011) research on men using methamphetamine showed that in the group of men who were non-relapse it was known to have higher self efficacy with lower craving (with a comparison of mean self efficacy in relapse and non relapse groups, 54.76 and 80.22 and the comparison of mean craving 49.98 and 28.47).

The same thing was stated by Fitrianti, Subekti, and Aquarisnawati (2011) who examined the effect of emotional maturity and self afficacy on former drug users, showing the results that the better self efficacy possessed, the individual would show an attitude of controlling or controlling emotions and making them happen through response good emotional with good responsibility too. The more developed the level of confidence and maturity of a person, the more capable the individual is to provide a good emotional response, so that it can overcome the strong desire to re-use narcotics or called craving. Other studies also found results that were not much different, namely the effect of self efficacy on low craving (Baumann \& Sayette, 2006). Self efficacy also plays a role in achieving goals. Self efficacy describes expectations of the results achieved, so it also determines behaviors that then arise (Bandura, 1997). Bandura (1997) suggests that individuals who have the necessary skills and strong self efficacy are more likely to mobilize the efforts needed to successfully fight high-risk situations for using narcotics or drinking alcohol. When experiencing conditions that make individuals fall, people who have high self efficacy tend to regard the condition as a temporary setback, then try to restore control to the situation, while individuals who have low self-efficacy tend to experience relapse.

It can be concluded that the purpose of this study is to see how much influence the severity of addiction and abstinence self efficacy on drug craving on stimulant drug users, where the hypothesis proposed is that there is influence of addiction severity and efficacy of drug craving in narcotics abusers.

\section{Research Methodes}

In this study, data was obtained through a questionnaire. There were 100 participants with characteristics, namely men, amphetamine type stimulant users, aged 20-40 years and were running a rehabilitation program. The questionnaire used consisted of Amphetamine Craving Questionnaire developed by Tiffany, Singleton, Haertzen, and Henningfield (1993) to measure drug craving, the Drug Abstinence Selfefficacy Scale developed by Diclemente, Carbonari, Montgomery, and Hughes (1994) to measure abstinence self efficacy, and Drug Abuse Screening Test (Maisto, Carey, Carey, Gordon \& Gleason, 2000) to see the severity of addiction. For amptehamine craving questionnaire and self efficacy scale abstinence, it is a questionnaire in the form of a Likert scale with 5 choices of answers, which are very appropriate, appropriate, neutral, inappropriate, and very inappropriate. While the Drug Abuse Screening test is a Guttman scale questionnaire with 2 answer choices, namely yes and no where if the respondent chooses the answer yes it will be given a score of 1 and if the respondent chooses no answer, then a score of 0 is given.

Amptehamine craving questionnaire has 30 items of statements and alpha cronbach's reliability value is 0.879 with item discrimination value above 0.30 , which is moving between 0.307 to 0.699 . The abstinence of self efficacy scale has 20 statements and the reliability value of alpha cronbach is 0.936 with the value of the discrimination power of items above 0.30 , which is moving between 0.492 to 0.743 . Data analysis in this 
research used multiple regression analysis which was carried out with the help of the SPSS version 21 program.

\section{Result and Discussion}

The results of this study were obtained from respondents who filled out the questionnaire. The results of the demographic data are obtained as follows:

Table 1. Demographic data of respondents

\begin{tabular}{lll}
\hline No & Demografic Data & F \\
\hline 1 & Age : & \\
& $20-25$ & 44 \\
& $26-30$ & 16 \\
& $31-35$ & 22 \\
& $36-40$ & 18 \\
2 & Abstinence : & \\
& 1 month & 9 \\
& 2 months & 37 \\
& 3 months & 33 \\
& 4 months & 21 \\
& Marital Status : & \\
& Single & 60 \\
& Married & 31 \\
& Widower & 9 \\
4 & Education : & \\
& Elementary school & 3 \\
& Junior high school & 6 \\
& Senior high school & 69 \\
& Diploma & 4 \\
& Bachelor & 17 \\
& Master & 1 \\
\hline
\end{tabular}

Regarding the average value of each variable, can be seen in the table below

Table 2. Descriptive Statistics

\begin{tabular}{lcc}
\hline Variable & Mean & Std Deviation \\
\hline Drug Craving & 23,28 & 7,120 \\
Severity of Addiction & 5,87 & 2,390 \\
Abstinence self efficacy & 22,33 & 7,496 \\
\hline
\end{tabular}


From the results of the analysis using multiple regression analysis, it can be seen that there is an effect of addiction severity and significant abstinence of self efficacy on drug craving together with a significance value of 0,000 ( $\mathrm{p}<0.05$ ) with a percentage of $29.9 \%$. The output can be seen in the following tables 3 and 4:

Table 3. Significance Value

\begin{tabular}{|c|c|c|c|c|c|c|}
\hline & del & Sum of Squares & $\mathrm{df}$ & Mean Square & $\mathrm{F}$ & Sig. \\
\hline \multirow[t]{3}{*}{1} & Regression & 1501,664 & 2 & 750,832 & 20,711 &, $000^{\mathrm{a}}$ \\
\hline & Residual & 3516,496 & 97 & 36,253 & & \\
\hline & Total & 5018,160 & 99 & & & \\
\hline
\end{tabular}

Table 4. Percentage of All Dependent Variable Influences

\begin{tabular}{lrrrr}
\hline Model & R & R Square & Adjust R Square & $\begin{array}{c}\text { Std. Error of the } \\
\text { Estimate }\end{array}$ \\
\hline 1 &, $547^{\mathrm{a}}$ &, 299 &, 285 & 6,021 \\
\hline
\end{tabular}

The Table 5 below shows the significance values and the percentage of each dependent variable for drug craving.

Table 5. Effective Influence on Dependent Variables

\begin{tabular}{llll}
\hline Independent Variable & Dependent Variabel & Significance Value & Percentage effect \\
\hline Severity of Addiction & Drug Craving & 0.000 & $36.6 \%$ \\
Abstinence Self Efficacy & Drug Craving & 0.001 & $-29.9 \%$
\end{tabular}

From the results above, it shows that the two independent variables, both the severity of addiction and the abstinence of self efficacy affect drug craving. The conditions of addiction both nicotine, alcohol, and narcotics in individuals, involve complex processes in the brain related to compulsive thinking which then raises the desire to consume the substance again. Where the more severe individual addiction, the stronger the activation of mesolimbic dopamine systems, so the desire to use these substances is also getting stronger. This is consistent with the research conducted by Hillemacher, Bayerlein, Wilhelm, Frieling, Thürauf, Ziegenbein, Kornhuber \& Bleich (2006) in 127 male smokers which showed that the severity of addiction was related to craving of alcohol. Where the higher the severity score, the higher the value of craving is found.

The severity of addiction can be seen in several aspects, which include health / physical problems, narcotics use, legal status, family problems, problems at school or workplace, problems with social activities and interactions, as well as the psychological status of narcotics abusers. Especially related to physical problems, the severity of addiction can be seen to what extent narcotics users feel withdrawl. This withdrawal is related to the high drug craving. Like research conducted by Mokri, Ekhtiari, Edalati, \& Ganjgahi (2008) in 26 male heroin users. This study shows that the high symptom withdrawl affects the height of craving. Other studies also found similar results, namely research conducted by Moak, Anton, \& Latham (1998) involving 
124 alcoholics, finding results that the severity of alcohol dependence related to craving was measured through obsessive-compulsive drinking scales.

The results of the study also show that abstinence self efficacy influences drug craving. Papalia, Old, and Feldman (2010) suggest that self efficacy is self-confidence and skill, that someone has the character they need to succeed. Wade and Tavris (2007) suggested that self-efficacy is a person's belief that he is able to achieve the desired results, such as mastering a new skill or achieving a goal. Further, Bandura (1997) explains that self efficacy is a personal or cognitive factor that is important in individual achievement. Self efficacy is the belief that "I can", while the absence of high self efficacy will use the belief that "I can't".

Santrock (2012) argues that self efficacy affects the choice of activities and tasks of individuals. Individuals with low self efficacy, may avoid some challenging tasks. Conversely, individuals with high self efficacy may be impatient to immediately complete their tasks, individuals with high self efficacy tend to spend more effort in taking the time to learn a task than individuals with low self efficacy. Furthermore, according to Bensley and Brookins-Fisher (2003) self-efficacy means believing that individuals have the ability to act and survive with their own business. This statement is in accordance with abstinence self efficacy which is the belief that individuals will be able to survive not using narcotics in certain situations and conditions.

When a user is faced with a situation whether he will use a substance or not is a high-risk situation, so relapse will depend on the expectation of his beliefs. The expectation of belief is the individual's belief in his ability to resist the temptation to consume substances. The outcom is the individual's beliefs about the effects of consuming substances or not consuming substances. Positive expectations, for example that if you consume substances he will feel comfortable, reduce pain, while negative expectations, for example if consuming substances will lose work. Positive expectations for narcotics can be influenced by low self efficacy. Some studies that show self efficacy have an effect on craving, namely research conducted by Minervini, Palandri, Bianchi, Bastiani, and Paffi (2011) on 80 dependents, shows that self efficacy has a negative effect on drug craving. Another study was conducted by Barta, Kurth, Stein, Tennen, and Kiene (2009) on 21 heroin users who were in rehabilitation. From the experimental results it was found that participants who had high self efficacy values found lower craving values.

Self-efficacy, especially in terms of addiction, relates to specific situations and potential risks of the situation, so that having high self-efficacy, recovering addict can be easier to recognize the most dangerous situations and measure their beliefs regarding these dangerous situations, so it is very important to have self efficacy in an effort to reduce drug craving and keep abstinence.

\section{Conclusion}

Based on the results of the research obtained, it can be concluded that there are significant effects of addiction and abstinence of self efficacy on drug craving on drug users of stimulant types who are carrying out rehabilitation programs.

\section{Suggestion}

For respondents, it is hoped that they can increase their confidence to stay away from narcotics in every condition so that they can suppress drug craving, so as to minimize the rate of relapse. For further researchers who are interested in researching the same variables, this research can improve so that it can produce better research, for example by using respondents with the use of other substances, or by involving also female respondents. Add other variables as independent variables, for example stress variables or self regulation and their effects on drug craving. 


\section{References}

Bandura, A. 1997. Self-efficacy: The exercise of control. New York : Macmillan.

Barta, W. D., Kurth, M. E., Stein, M. D., Tennen, H., Kiene, S. M. 2009. Craving and self-efficacy in the first five weeks of methadone maintenance therapy: a daily process study. Journal of studies on alcohol and drugs, 70(5), 735-740.

Baumann, S. B., Sayette, M. A. 2006. Smoking cues in a virtual world provoke craving in cigarette smokers. Psychology of Addictive Behaviors, 20(4), 484.

Bensley, R. J., Brookins-Fisher, J. (Eds.). 2003. Community health education methods: A practical guide. Jones \& Bartlett Learning.

Canterberry, M., Hanlon, C. A., Hartwell, K. J., Li, X., Owens, M., LeMatty, T., ... George, M. S. 2013. Sustained reduction of nicotine craving with real-time neurofeedback: exploring the role of severity of dependence. Nicotine \& tobacco research, 15(12), 21202124.

Chong, J. Lopez, D. 2008. Predictors of relapse for american indian women after substance abuse treatment. American Indian and Alaska Native Mental Health Research: The Journal of the National Center. Vol 14, No. 3, 24-48.

De Los Cobos, J. P., SiÑol, N., Trujols, J., BaÑuls, E., Batlle, F., Tejero, A. 2011. Drug-dependent inpatients reporting continuous absence of spontaneous drug craving for the main substance throughout detoxification treatment. Drug and alcohol review, 30(4), 403-410

DiClemente, C. C., Carbonari, J. P., Montgomery, R. P., Hughes, S. O. 1994. The alcohol abstinence self-efficacy scale. Journal of studies on alcohol, 55(2), 141-148.

Ekhtiari, H., Nasseri, P., Yavari, F., Mokri, A., Monterosso, J. 2016. Neuroscience of drug craving for addiction medicine: From circuits to therapies. In Progress in brain research (Vol. 223, pp. 115-141). Elsevier.

Fitrianti, N., Subekti, E.M.A., Aquarisnawati, P. 2011. Pengaruh antara kematangan emosi dan self-eficacy terhadap craving pada mantan pengguna narkoba. INSAN Vol. 13 No. 02, 106-117.

Fleischhacker, W.W. Brooks, D.J. 2003. Addiction, mechanism, phenomenology, and treatment. London : Springer.

Funk, D., Coen, K., Tamadon, S., Hope, B. T., Shaham, Y., Lê, A. D. 2016. Role of central amygdala neuronal ensembles in incubation of nicotine craving. Journal of Neuroscience, 36(33), 8612-8623.

Girardeau, P., Navailles, S., Durand, A., Vouillac-Mendoza, C., Guillem, K., Ahmed, S. H. 2016. Persistent vulnerability to relapse despite complete extinction of cocaine craving. bioRxiv, 050401.

Hall, W., Carter, A., Forlini, C. 2015. The brain disease model of addiction: is it supported by the evidence and has it delivered on its promises?. The Lancet Psychiatry, 2(1), 105-110.

Hillemacher, T., Bayerlein, K., Wilhelm, J., Frieling, H., Thürauf, N., Ziegenbein, M., ... Bleich, S. 2006. Nicotine dependence is associated with compulsive alcohol craving. Addiction (Abingdon, England), 101(6), 892-897.

Kamboj, S. K., Das, R. K. 2017. Behavioral and pharmacological strategies for weakening maladaptive reward memories: a new approach to treating a core disease mechanism in tobacco use disorder. JAMA psychiatry, 74(3), 209-211.

Killen, J. D., Fortmann, S. P. 1997. Craving is associated with smoking relapse: findings from three prospective studies. Experimental and Clinical Psychopharmacology, 5(2), 137.

Knäuper, B., Pillay, R., Lacaille, J., McCollam, A., Kelso, E. 2011. Replacing craving imagery with alternative pleasant imagery reduces craving intensity. Appetite, 57(1), 173-178.

Kutlu, M. G., Gould, T. J. 2016. Effects of drugs of abuse on hippocampal plasticity and hippocampus-dependent learning and memory: contributions to development and maintenance of addiction. Learning \& Memory, 23(10), 515-533.

Maisto, S. A., Carey, M. P., Carey, K. B., Gordon, C. M., Gleason, J. R. 2000. Use of the AUDIT and the DAST-10 to identify alcohol and drug use disorders among adults with a severe and persistent mental illness. Psychological assessment, 12(2), 186. 
McGhee, L.K.C. 2011. Drug addiction : Diseases and disorders. San Diego : Reference Point Press.

Melander. 2002. Health psychology: Integrating mind and body. Singapore: Allyn and Bacon.

Minervini, I., Palandri, S., Bianchi, S., Bastiani, L., Paffi, D. 2011. Desire and coping self-efficacy as craving measures in addiction: The Self-Efficacy and Desire Scale (SAD). Open Behavioral Science Journal, 5, 1-7.

Moak, D. H., Anton, R. F., Latham, P. K. 1998. Further Validation of the Obsessive-Compulsive Drinking Scale (OCDS) Relationship to Alcoholism Severity. The American journal on addictions, 7(1), 14-23.

Mokri, A., Ekhtiari, H., Edalati, H., Ganjgahi, H. 2008. Relationship between degree of craving and different dimensions of addiction severity in heroin intravenous users. Iranian Journal of Psychiatry and Clinical Psychology, 14(3), 298-306.

Nutt, D.J. Nestor, L.J. 2013. Addiction. New York : Oxford University Press.

Padula, C. B., McQueeny, T., Lisdahl, K. M., Price, J. S., Tapert, S. F. 2015. Craving is associated with amygdala volumes in adolescent marijuana users during abstinence. The American journal of drug and alcohol abuse, 41(2), 127-132.Silva, R. J. M., Galinato, M. H., \& Mandyam, C. (2016). Role of Hippocampal Neurogenesis in Drug Addiction. The FASEB Journal, 30(1_supplement), 5184.

Papalia, D. E., Old, S. W., Feldman, R. D. 2010. Human development. Jakarta : Kencana Prenada Media Group.

Santrock, J.W. 2012. Lifespan developmental psychology. New York : Mc Graw Hill.

Schneekloth, T.d., Biernacka, J.M., Hall-Flav, D.K., Karpyak, V.M., Frye, M.A., Loukianova, L.L., Stevens, S.R., Drews, M.S., Geske, J.R., Mrazek, D.A. 2012. Alcohol craving as a predictor of relapse. The American Journal on Addictions. 21, S20-S26.

Skorka-Brown, J., Andrade, J., Whalley, B., May, J. 2015. Playing Tetris decreases drug and other cravings in real world settings. Addictive Behaviors, 51, 165-170.

Thakar, V. 2006. Addiction. New York : Chelsea House Publishers.

Soenksen, S., Stein, L. A. R., Brown, J. D., Stengel, J. R., Rossi, J. S., Lebeau, R. 2015. Cannabis withdrawal among detained adolescents: exploring the impact of nicotine and race.Journal of child \& adolescent substance abuse, 24(2), $119-124$.

Tiffany, S. T., Singleton, E., Haertzen, C. A., Henningfield, J. E. 1993. The development of a cocaine craving questionnaire.Drug and alcohol dependence, 34(1), 19-28.

Tuliau, A.P Liwag, D. 2011. Predictors of relapse in filipino male methamphetamine users : A mixed methods approach. Journal of Ethnicity in Substance Abuse, 10. 162-179.

Venniro, M., Caprioli, D., Shaham, Y. 2018. Novel models of drug relapse and craving after voluntary abstinence. Neuropsychopharmacology: official publication of the American College of Neuropsychopharmacology, 44(1), 234235 .

Volkow, N. D., Fowler, J. S., Wang, G. J., Telang, F., Logan, J., Jayne, M. Swanson, J. M. 2010. Cognitive control of drug craving inhibits brain reward regions in cocaine abusers. Neuroimage, 49(3), 2536-2543.

Vollstädt-Klein, S., Kobiella, A., Bühler, M., Graf, C., Fehr, C., Mann, K., Smolka, M. N. 2011. Severity of dependence modulates smokers' neuronal cue reactivity and cigarette craving elicited by tobacco advertisement. Addiction Biology, 16(1), 166-175.

Wade, C., Tavris, C. 2007. Psikologi edisi kesembilan jilid 2. Jakarta: Penerbit Erlangga. 